\title{
Peroxiredoxins, gerontogenes linking aging to genome instability and cancer
}

\author{
Thomas Nyström, ${ }^{1}$ Junsheng Yang, and Mikael Molin \\ Department of Cell and Molecular Biology, University of Gothenburg, 41390 Göteborg, Sweden
}

\begin{abstract}
Age is the highest risk factor known for a large number of maladies, including cancers. However, it is unclear how aging mechanistically predisposes the organism to such diseases and which gene products are the primary targets of the aging process. Recent studies suggest that peroxiredoxins, antioxidant enzymes preventing tumor development, are targets of age-related deterioration and that bolstering their activity (e.g., by caloric restriction) extends cellular life span. This review focuses on how the peroxiredoxin functions (i.e., as peroxidases, signal transducers, and molecular chaperones) fit with contemporary theories of aging and whether peroxiredoxins could be targeted therapeutically in the treatment of age-associated cancers.
\end{abstract}

The life span of most organisms, from single-cell species to humans, is inherently restricted and involves genetic elements of regulation. The term "gerontogene" is used to signify such a genetic element, which influences an organism's life span by affecting the rate and/or onset of aging (Rattan 1995). This does not mean that gerontogenes are "programming" aging; the existence of such programming genes has been disputed on the basis of evolutionary arguments against the adaptive nature of aging (e.g., Medawar 1952; Hamilton 1966). Therefore, as these genetic entities were not originally selected as genes/alleles for or against aging, but are rather involved in aging as an emergent property (by-product), it has been suggested that they should be called "virtual gerontogenes" (Rattan 1995).

Operationally, gerontogenes are defined as genetic elements that can, when altered one way or the other, extend life span beyond what is normal for the specific species concerned. Such genetic alterations include increased gene dosage and partial or complete inactivation. The latter class is exemplified by the first gerontogene mutation identified, age-1, of the nematode Caenorhabditis elegans (Klass 1983; Friedman and Johnson 1988). Gerontogenes have subsequently been identified in many

[Keywords: aging; peroxiredoxin; gerontogenes; genome instability; cancer; chemotherapy]

${ }^{1}$ Corresponding author

E-mail thomas.nystrom@cmb.gu.se

Article is online at http://www.genesdev.org/cgi/doi/10.1101/gad.200006.112. organisms, including yeast, flies, and mice (e.g., Guarente 2000; Jazwinski 2002; Fontana et al. 2010; Kenyon 2010), and potentially important genetic markers for slow aging have been found in humans (Suh et al. 2008). Elucidating the function of such genes is believed to enable deciphering the core of the aging process, answer to what extent the process is conserved, and pave the way for therapeutic interventions of age-related maladies, including cancers, neurodegeneration, and metabolic syndrome (Guarente 2011).

The identity of the virtual gerontogenes so far discovered in diverse taxa suggests, at least superficially, that a restricted set of signaling pathways controls the rate of aging. Specifically, aging is decelerated by mutations reducing signaling through nutrient-responsive pathways, including insulin/insulin-like growth factor, $\mathrm{mTOR}$, and RAS-PKA signaling (Cohen and Dillin 2008; Kenyon 2010; Bartke 2011; McCormick et al. 2011). Such a reduced activity in nutrient-responsive pathways results in the altered expression of a large number of genes, and it is presently not clear which of all of these genes are the most crucial targets responsible for life span extension. This is problematic, since hitting entire nutrient signaling pathways therapeutically has its obvious drawbacks and risks. The sirtuins, notably the paradigm SIR2 in yeast, represent another class of gerontogenes-deletion of SIR2 accelerates aging, whereas extra copies of the gene result in life span extension (Kaeberlein et al. 1999; Guarente 2000). The sirtuins are histone/protein deacetylases, and the role of Sir2 in regulating replicative longevity in yeast is linked, in part, to its role in stabilizing the genome, specifically by preventing recombination at the rDNA locus and the accumulation of extrachromosomal rDNA circles (ERCs) (Sinclair and Guarente 1997). Similarly, specific sirtuins affect the stability of the aging genome also in mammalian cells (Mostoslavsky et al. 2006; Oberdoerffer et al. 2008). Sir2-dependent control of yeast aging appears interconnected with nutrient signaling, as reduced activity of TOR extends replicative life span, at least in part, by boosting Sir2 activity (Anderson et al. 2003; Medvedik et al. 2007; see also Steffen et al. 2008). Likewise, life span extension achieved by reducing the activity of the yeast mitochondrial translation control module (MTC) acts through Sir2 activation (Caballero et al. 2011).

Alongside the sirtuins, genes encoding the peroxiredoxins (Prxs) have recently emerged as a new class 
of gerontogenes that link aging to genome stability and nutrient-responsive signaling. For example, a neuronal Prx, Jafrac1, in Drosophila acts as a downstream effector of the nutrient-responsive transcription factor FOXO in life span extension (Lee et al. 2009). Likewise, the major cytosolic Prx of budding yeast, Tsa 1, and its repair enzyme, the sulfiredoxin (Srx) Srxl, are downstream targets for nutrient-responsive (RAS-PKA) signaling, and bolstering their activity extends life span (Molin et al. 2011). These results highlight new and intriguing potential inroads in therapeutic gerontology, and this review focuses on how the Prx functions (i.e., as peroxidases, signaling enzymes, and molecular chaperones) may affect genome stability and the rate of aging, how this fits with the free radical hypothesis of aging, and whether Prxs could be targeted therapeutically in the treatment of age-related cancers and/or chemotherapy resistance.

\section{Prxs and their repair enzymes}

Prxs act as hydrogen peroxide and organic hydroperoxide scavengers. They all use cysteine (Cys) as the primary site of oxidation and are divided into the 1-Cys and 2-Cys groups based on the number of conserved Cys residues participating in the redox reaction. The 2-Cys Prxs are further divided into the "typical" and "atypical" ones: The typical ones form homodimers through an intersubunit disulfide bond (Fig. 1), whereas the atypical ones form a monomer with an intramolecular disulfide bond during hydrogen peroxide catalysis (D'Autreaux and Toledano 2007). The yeast Prx most significantly contributing to peroxide resistance, genome stability, and antimutation is the typical 2-Cys Prx Tsal (Fourquet et al. 2008; Iraqui et al. 2009); the human functional homolog is Prdx1 (Iraqui et al. 2008).

Interestingly, eukaryotic Prxs are exquisitely sensitive to hyperoxidation and inactivation. Specifically, the active Cys-thiol is prone to become hyperoxidized to Cyssulfinic acid (Fig. 1), which is specifically reduced by Srxs in organisms from yeast (Biteau et al. 2003) to humans (Woo et al. 2005). In the absence of Srxs, typical Prxs become "locked" in the hyperoxidized, peroxide scavenger-deficient form upon peroxide stress (Fig. 1). All the same, structural features that stabilize the hyperoxidized forms seem to have been selected for in the evolution of eukaryotic Prxs, suggesting that such hyperoxidation might provide a distinct and ostensibly advantageous function (Wood et al. 2003a). Specifically, the peroxidesensitive 2-Cys Prxs have been suggested to act as "floodgates" such that their inactivation by sulfinylation allows peroxide levels to rise above a certain threshold needed for signal transduction (Wood et al. 2003a). In response to growth factor stimulation, it has been shown that localized inactivation of a target Prx in specific tissues may also involve phosphorylation that appears to coincide with sites of growth factor-dependent hydrogen peroxide production (Woo et al. 2010; Rhee et al. 2012). Other results in line with a beneficial role for hyperoxidation show that the sulfinylated forms of the

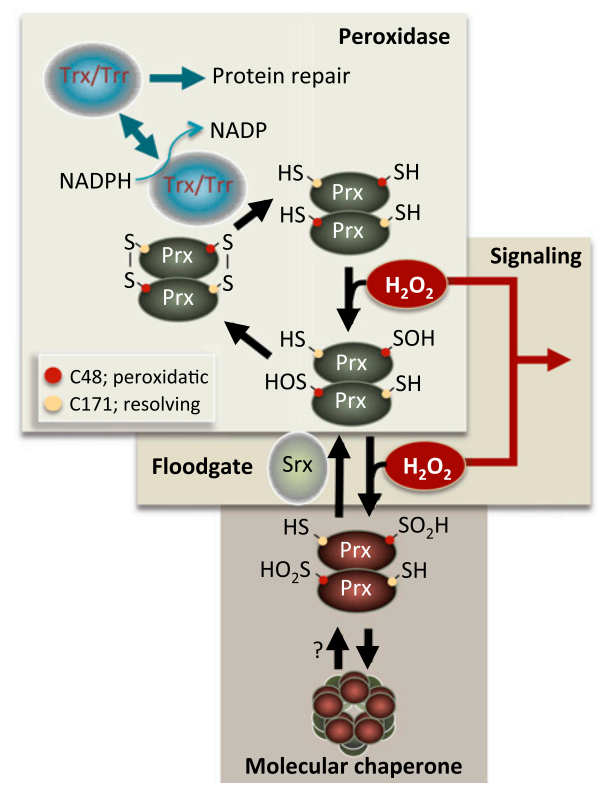

Figure 1. Overview of catalysis in typical 2-Cys Prx. Hydrogen peroxide $\left(\mathrm{H}_{2} \mathrm{O}_{2}\right)$ is reduced by the peroxidatic Cys that is oxidized to a sulfenic acid intermediate (C48-SOH in yeast). The nascent R-SOH then condenses with the resolving Cys (C171-SH in yeast) of the other Prx molecule in the Prx dimer to produce a disulfide bond. This bond is subsequently reduced by Trx, thus completing the catalytic cycle. A proportion of Cys$\mathrm{SOH}$ molecules can be further oxidized (hyperoxidation) to the sulfinic acid form (Cys-SOOH) in each catalytic cycle, which inactivates peroxidase activity (Wood et al. 2003b). Srxs reduce the sulfinylated forms of 2-Cys Prxs (Biteau et al. 2003; Woo et al. 2005), which allows Prx to re-enter the catalytic, peroxidatic cycle. The hyperoxidized form of $\operatorname{Prx}$ forms oligomers (Hall et al. 2011; Saccoccia et al. 2012) that act as molecular chaperones (i.e., inhibit protein aggregation in vitro) (Jang et al. 2004). The boxes denote three principal Prx activities that may affect genome stability and life span: (1) peroxidase activity reducing the levels of harmful peroxides, (2) hyperoxidation by the "floodgate reaction" allowing peroxide levels to reach local thresholds as a second messenger in signal transduction, and (3) hyperoxidation leading to Prx oligomer formation and molecular chaperone activity. (Trr) Trx reductase.

yeast Prx Tsal multimerize and gain a molecular chaperone activity (Fig. 1); i.e., multimer Tsal inhibits the aggregation of model protein substrates such as insulin in vitro (Jang et al. 2004; Lim et al. 2008). Recent structural analysis suggests that the hyperoxidized chaperone form of Prx is a double decamer; i.e., it consists of two "sandwiched" decamer rings (Saccoccia et al. 2012). Oxidative stress (peroxide) triggers the peroxidase-to-chaperone switch, which in yeast is guided by the Cys 48 residue on Tsa1. Therefore, it has been proposed that 2-Cys Prxs serve as redox sensors in the cell that, depending on the severity of oxidative insults, may act as a peroxidase, molecular chaperone, or both (Jang et al. 2004). In addition, it has recently been shown that hyperoxidation of Prxs may be beneficial upon severe peroxide stress also by an indirect effect. Specifically, Prx heterodimers engaged in the catalytic cycle upon low-level hydrogen peroxide 
stress appear to be a main target for thioredoxin (Trx) (Fig. 1). However, the sulfinylated form of Prx is not a target for reduction by Trx (Fig. 1), and it was therefore proposed that more Trx becomes available for the reduction of other oxidatively damaged enzymes upon Prx hyperoxidation (Day et al. 2012).

Notably, some eukaryotes, including C. elegans, appear to lack Srxs and the means to reduce hyperoxidized Prxs. Possibly, sestrins might be able to reduce hyperoxidized Prx (Budanov et al. 2004) in organisms lacking Srxs, but the sestrins do not carry sulfinic acid reductase activity (Woo et al. 2009), and it is unclear whether hyperoxidation of Prx in organisms lacking Srxs is physiologically relevant (Olahova et al. 2008; Woo et al. 2009; Thamsen et al. 2011).

\section{Links between aging, caloric restriction (CR),} and Prx activity

Prx deficiency results in accelerated aging in yeast, worms, flies, and rodents (Neumann et al. 2003; Olahova et al. 2008; Lee et al. 2009; Timmermann et al. 2010). Moreover, the yeast and rat Prxs, Tsal and PrxII, are becoming increasingly hyperoxidized during aging in the absence of external peroxide stress (Musicco et al. 2009; Molin et al. 2011), indicating that Prx inactivation may be a common phenomenon in different aging organisms. Thus, like Sir2 (Dang et al. 2009), the activity of the major Prx of yeast is reduced during aging, indicating that the yeast genome may become destabilized, in part, because proteins involved in both silencing/chromatin organization (Sir2) (Dang et al. 2009) and anti-mutation (Tsal) (Molin et al. 2011) are themselves inactivated or produced in limiting amounts in aging cells. This is consistent with the hypothesis of McMurray and Gottschling (2003, 2004), which suggests that accumulation of oxidatively damaged proteins in aging cells results in the loss of function of gene products critical for maintaining genome integrity and points out that determining the identity of these proteins and how they become damaged represents a new challenge for understanding the relationship between age, genomic instability, and cancer. In addition, age-associated genome instability (i.e., mitotic recombination in the yeast rRNA gene cluster) is the result also of Sir2-independent processes (Lindstrom et al. 2011). Furthermore, nuclear genome instability induced by ageassociated mitochondrial dysfunctions has been linked to defects in iron-sulfur biogenesis that in turn were hypothesized to inactivate key DNA repair enzymes (Veatch et al. 2009).

With respect to the Prxs, it is not clear how aging affects their oxidation, but sulfinylation may be the result of endogenously elevated levels of hydrogen peroxide, as the levels of this oxidant have been shown to increase with the replicative age of yeast mother cells (Laun et al. 2001; Erjavec and Nystrom 2007) and with the chronological age of both rats and mice (Andres-Mateos et al. 2007; Asha Devi et al. 2011). In conjunction with this, old cells appear to have a diminished capacity for Srx-dependent reduction of Prxs, and providing yeast cells with an extra copy of the SRX1 gene counteracts age-related hyperoxidation of Tsal (Molin et al. 2011). Remarkably, an extra copy of $S R X 1$ also extends life span by $20 \%$ in a TSA1-dependent manner (Molin et al. 2011). This life span extension by $S R X 1$ merodiploidity is similar to that achieved by an extra copy of SIR2 (Kaeberlein et al. 1999, 2004) and is effective also in the absence of Sir2 (Molin et al. 2011).

$\mathrm{CR}$, a practice that prolongs life span in taxonomically diverse organisms (Fontana et al. 2010; Kenyon 2010; McCormick et al. 2011), counteracts sulfinylation of Tsa 1 during aging in an Srx1-dependent manner (Molin et al. 2011). Specifically, a CR-induced reduction in RAS-PKA signaling bolsters Gcn2-dependent translation of the $S R X 1$ transcript (Fig. 2). Apart from counteracting Tsa1 sulfinylation, this boost in $S R X 1$ translation appears to be an imperative part of CR-dependent life span extension, as CR fails to efficiently extend life span in cells lacking either Tsa1 or Srx1 (Molin et al. 2011). Again, Tsa1/Srx1dependent life span extension reached by CR works in both the presence and absence of SIR2, suggesting that Tsa 1 and Sir2 act in parallel pathways of life span control.

In summary, data supporting a link between Prx activity and aging include the following: (1) Yeast, worms, flies, and rodents with diminished Prx activity age prematurely. (2) Aging causes hyperoxidation (sulfinylation) of Prxs, which diminishes their catalytic activity. (3) Counteracting Prx sulfinylation and bolstering Prx activ-
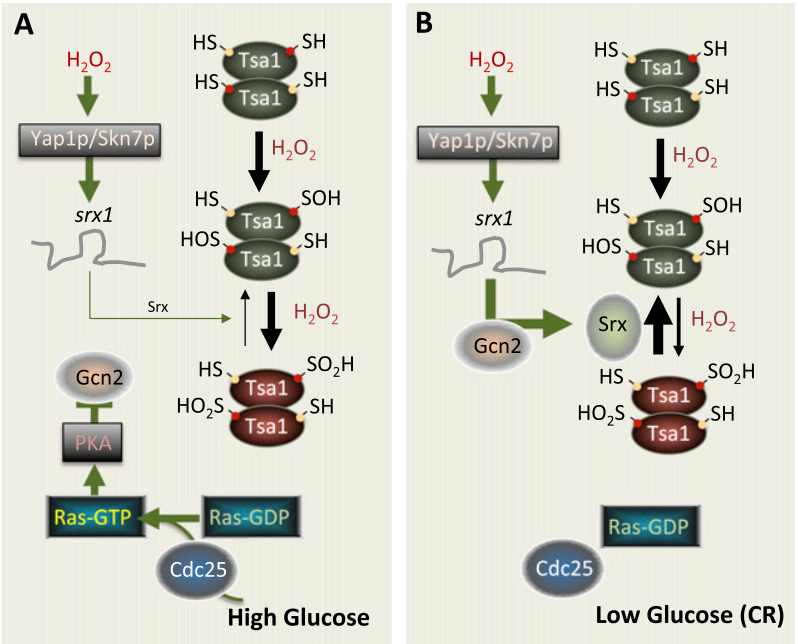

Figure 2. Schematic representation of how CR, through RASPKA signaling, sustains yeast Prx catalytic activity. (A) At a high concentration of glucose, leading to a high RAS-cAMP-PKA activity, hydrogen peroxide can activate Yap1/Skn7-dependent transcription of the SRX1 mRNA, but its translation is inhibited by PKA. In the absence of Srx, a large portion of Tsal becomes hyperoxidized and inactivated. (B) During CR, Ras-PKA activity is reduced, and this relieves the translational inhibition of the $S R X 1$ mRNA in a Gcn2-dependent manner to provide more Srxl protein and, as a consequence, more reduced peroxidaseactive Tsa1. Conditional mutations in Cdc25 reduce Ras activity, create a phenocopy of CR, and extend life span in a Tsa1dependent manner (Molin et al. 2011). 
ity in yeast by elevating the levels of its repair enzyme, Srx1, extend life span. (4) CR, by elevating Prx activity through augmented Srx1-dependent repair, slows replicative aging.

\section{Prxs and the free radical hypothesis of aging}

The evolved version of Harman's (Harman 2003) free radical theory of aging proposes that organisms age because the constituents of cells and tissues accumulate damage over time caused by reactive oxygen (and/or nitrogen) species originating from endogenous metabolism, including, among many other possible activities, mitochondrial respiration. At first glance, it appears that the data concerning Prxs and aging fit this theory like a glove, as Prxs become "damaged" (catalytically inactivated as a peroxidase) during aging due to a modification caused by a reactive oxygen species (ROS), specifically hydrogen peroxide (or organic hydroperoxides), and that counteracting this "damage" by elevating the levels of the "repair" enzyme Srxl prolongs life span (Molin et al. 2011). Moreover, as the Prxs themselves act as enzymatic antioxidants and protect the genome against oxidative modifications (see below), it is possible that peroxidedependent inactivation of Prxs gives rise to a negative feedback loop with respect to the cell's capacity for ROS homeostasis.

On the other hand, it could be questioned whether the sulfinylation of typical 2-Cys Prxs by hydrogen peroxide should be regarded as damage per se. Rather, hydrogen peroxide could be considered an effector/signaling molecule triggering a switch in Prx functions-a reversible redox switch under control of Srxs (Wood et al. 2003a; D'Autreaux and Toledano 2007). This redox switch may be critical for modulating signaling through proliferation, checkpoint, and cell cycle regulatory pathways (see below), and such control could potentially be more important than peroxide scavenging in protecting the genome, suppressing tumorigenesis, and assuring longevity. Likewise, the chaperone functions of the sulfinylated Prxs could be critical in defending the cells against cytotoxic stress and affect the rate of aging. However, it should be noted that the Prxs are exquisitely suitable as scavengers of low concentrations of endogenously generated peroxides in protecting the genome (D'Autreaux and Toledano 2007; Fourquet et al. 2008; Hall et al. 2011), and it cannot be ruled out that this is the major reason for life span extension by increasing Prx function in aging cells (Molin et al. 2011). Nevertheless, the fact that Prxs and Srx act as gerontogenes does not on its own support the free radical hypothesis of aging, but deciphering the exact biochemical role of the Prxs in life span extension should resolve this issue.

\section{Links between genome instability, cancer, and Prx activity}

Before being recognized as gerontogenes, Prxs have received special attention in cancer research due to their association with signaling cascades, growth control, tumor suppression, and chemotherapy resistance (Neumann et al. 2003; Chen et al. 2006; Neumann and Fang 2007). To wit, deletion of yeast TSA1 causes a drastic loss of genome stability, gross chromosomal rearrangements (GCRs), and increased occurrence of base substitutions and frameshift mutations (Iraqui et al. 2008, 2009). In fact, Tsa 1 is absolutely required for cell survival in the absence of functional, Rad51/Rad52-dependent, recombinational repair or Rad6-mediated post-replication repair (Huang and Kolodner 2005). In addition, mice lacking PrdxI display an increased risk of developing hemolytic anemia and acquire several malignant cancers prematurely during aging, and their fibroblasts contain increased levels of oxidatively damaged DNA (Neumann et al. 2003). However, it remains to be established whether Prxs act as tumor suppressors in organisms other than mice and in preventing tumors other than lymphoid tumors.

But how do Prxs protect the genome? One possibility is that the spontaneous genome instability and cell death associated with Prxl deficiency is primarily linked to Prxs functioning as peroxide scavengers. In support of this view, Tsal deficiency combined with deficiencies in Ogg1, a glycosylase that removes 7,8-dihydro-8-oxo-2'deoxyguanosine (8-oxo-dG; a major, mutagenic product of DNA oxidation) results in markedly elevated mutation rates (Huang and Kolodner 2005). Furthermore, the increased mutation rate in tsa1 cells is suppressed by anaerobiosis (Ragu et al. 2007). However, in contrast to Ogg1-deficient cells, where the mutation rate returns to wild-type levels in the absence of oxygen (Northam et al. 2010), a tsa1 mutant has a somewhat higher mutation rate than wild-type cells also in the absence of oxygen (Ragu et al. 2007).

Studies in which mutations in the yeast Prx gene TSA1 are combined with DNA repair or cell cycle checkpoint defects provide additional insights into possible causes of increased genomic damage and mutations in Prx-deficient cells. For example, the removal of mismatch repair (MMR) proteins Msh2 or Msh6 in a tsa1 mutant results in a more than additive elevation of base substitutions and frameshifts without increasing GCRs (Huang and Kolodner 2005). In contrast, combining a deletion in DUN1, encoding the protein kinase of the Mec1-Rad53-Dun1 cascade, with tsa1s causes a synergistic increase in the rate of GCR while actually suppressing base substitutions and frameshifts (Huang and Kolodner 2005; Tang et al. 2009). The Mec1-Rad53-Dun1 pathway is crucial for DNA damage-induced up-regulation of the ribonucleotide reductase $(R N R)$, which in turn increases dNTP levels (Niida et al. 2010). Specifically, the Dun1-dependent elevation of $R N R$ expression and dNTP levels in a tsa1s mutant as shown by Tang et al. (2009) probably leads to a more efficient translesion DNA synthesis (TLS) (Sabouri et al. 2008) that may serve as a response to deal with DNA damage triggered by the absence of Tsal. However, the trade-off for this damage repair response is a TLS-dependent increase in mutation rates. Recently, $R N R$ induction and expansion of dNTP pools were recorded in tsa1s and other genome instability mutants deficient in various seemingly unrelated processes (repli- 
cation fork progression, recombinational repair, and sister chromatid cohesion) (Davidson et al. 2012; Poli et al. 2012). By analyzing these data, it appears as if a tsa1s mutant displays higher mutation rates than expected from the dNTP pools alone, suggesting that Tsal deficiency results in additional problems related to mutation protection. Recent results indicate that such additional problems may be related to tsa1s mutants failing to block replication fork progression upon DNA damage (exposure to the RNP inhibitor hydroxyurea) (Davidson et al. 2012).

Similar to Tsa1-deficient yeast, Prdx1-deficient mice contain higher levels of 8-oxo-dG (Neumann et al. 2003) and accumulate oxidatively modified DNA nucleosides in different tissues (Egler et al. 2005). However, no direct correlation could be established between the levels of DNA oxidation and tumor susceptibility (Egler et al. 2005), indicating that PrdxI may suppress tumorigenesis by mechanisms other than protecting the genome directly against oxidative attack; for example, by affecting cell cycle signaling. In line with this notion, PrdxI deficiency increases c-Myc activity (Egler et al. 2005) as well as Akt activity, the latter of which has been argued to result from the accumulation of the oxidatively inactivated PTEN phosphatase (Cao et al. 2009). Moreover, PrdxI inhibits c-Abl tyrosine kinase activity (Wen and Van Etten 1997), and overexpression of PrdxI inhibits c-Myc-mediated transformation of mouse embryonic fibroblasts (Mu et al. 2002). PrdxI has also been reported to negatively regulate Ask1 (apoptosis signal-regulating kinase 1) activation in response to hydrogen peroxide stress (Kim et al. 2008), a response that critically modulates chemically induced skin tumorigenesis in mice (Iriyama et al. 2009). The Ask1-mediated stress response was proposed to involve both tumor-suppressing p38/c-Jun N-terminal kinase-mediated apoptosis of initiated cells and tumor-promoting p38-mediated inflammation in later tumor stages (Iriyama et al. 2009).

Taken together, current evidence suggests that (1) loss of Prx increases a wide range of DNA damage, the repair of which involves diverse pathways and checkpoints; (2) genome instability in Prx-deficient cells is partly, but not entirely, due to an oxidation-dependent attack of DNA; (3) aberrant signaling through proliferation/cell cycle control pathways may contribute to genome instability and tumorigenesis in cells with aberrant Prx expression; and (4) the mutator phenotype of cells lacking Prxs is partially due to elevated dNTP pools and TLS and, possibly, defects in replication fork progression control. To what extent the chaperone function of sulfinylated Prxs contributes to genome stability (or chemotherapy resistance; see below) is an intriguing question that remains to be elucidated.

\section{Links between chemotherapy resistance and Prx activity}

Apart from the fact that Prxs act as tumor suppressors, Prxs have attracted attention in cancer research also due to the fact that their levels are drastically elevated in many cancer tissues and immortalized cell lines (Neumann and Fang 2007), which can lead to increased resistance to both radiotherapy and chemotherapy (e.g., cisplatin resistance) (Chung et al. 2001). Specifically, increased PRX expression has been reported in several studies of both lung cancer and breast cancer (Noh et al. 2001; Park et al. 2006). With respect to human lung cancer, differential $P R X$ expression was reported for various tumor subtypes, including adenocarcinoma and high-grade squamous cell carcinoma, as well as advanced tumor stages (Chen et al. 2006). Interestingly, modified (presumably oxidized) PrdxI accumulates in human lung cancer samples (Park et al. 2006), indicating, perhaps, a role for the chaperone function of PrdxI in tumorigenesis (or elevated peroxide signaling). Furthermore, a recent study reported that increased Srx expression deregulates PrdxIV activity in lung cancers, and Srx and PrdxIV were found to be required for several key aspects of tumor growth and metastasis; e.g., anchorage-dependent colony formation, cell migration, and invasion (Wei et al. 2011). In a previous study, increased Srx expression was observed also in several types of skin cancers (Wei et al. 2008), indicating that deregulation of Prx activity may be involved in several types of human cancers.

Similar to Prxs, both Trx and Trx reductase (Trr) levels are increased in several human cancers (Berggren et al. 1996; Park et al. 2006), and overproduction of Trx in MCF-7 human breast cancer cells induced tumorigenesis in a manner dependent on the catalytic cysteines (Gallegos et al. 1996). A detailed description of the roles of the Trxs in tumorigenesis is beyond the scope of this review, but it should be noted that increased Trx levels contribute to many of the hallmarks of cancer, including increased proliferation, resistance to apoptosis, and increased angiogenesis (Powis and Kirkpatrick 2007). Moreover, an inhibitor, PX-12, of the catalytic cysteines of Trx is currently under clinical development as an anti-tumor agent, and in a phase I study, a decrease in circulating Trx-1 levels upon PX-12 administration was demonstrated to increase the survival of patients with advanced refractory solid tumors (Ramanathan et al. 2007). Like for Prx, an uncontrolled and elevated Trx activity in cancer tissues constitutes a recognizable clinical problem, as Trx overproduction renders tumor cells resistant to therapy.

Based on the problems associated with Prx overexpression in both chemotherapy and radiotherapy, it has been proposed that inactivation of Prx enzymes may be a promising approach to improve the treatment outcome of cancer patients (Chen et al. 2006). However, in view of the fact that a diminished Prx activity in noncancerous tissue cells results in the loss of genome maintenance, promotes tumor development, and accelerates aging, treatments aimed at reducing Prx levels could potentially be risky and even counterproductive.

\section{Future perspectives}

Does the dual role of Prxs in chemotherapy resistance and tumor suppression make them unsuitable targets for therapy? Perhaps not—as outlined here, the biochemical 
functions of the Prxs are multifaceted, and it is possible that Prx activities associated with age-related tumor development are distinct from the ones providing resistance to chemotherapy/radiotherapy. Elevated Prx activity may protect a cancer cell against chemotherapy by means other than protecting its genome against oxidative attack; for example, by enhancing the cell's ability to deal with protein damage, such as stress-induced protein aggregation and proteotoxicity. In other words, it is possible that the established role of Prxs as anti-mutators/tumor suppressors on the one hand and protectors against chemotherapy on the other is provided by different, biochemical functions and forms of the Prxs, which could allow targeting one discrete function without blocking the others. For example, hyperoxidation of Prx may protect cancer cells against chemotherapy/ radiotherapy in two ways: first, by directly converting Prx to a molecular chaperone (Jang et al. 2004), and second, by allowing more Trx to participate in the repair of other damaged proteins, as the hyperoxidized Prx is no longer a substrate for Trx (Day et al. 2012). In this context, it would be interesting to learn whether the formation of Prx double decamers can be targeted therapeutically-an exciting possibility worth pursuing.

In view of the clinically established problems related to aberrant and elevated Prx production in treating agerelated cancers, approaching these possibilities and hypotheses experimentally may provide the means for future drug treatment improvements. Moreover, illuminating which Prx functions are critical for life span extension should give new and general insights into the aging process and its specific targets, a knowledge that in itself could guide future approaches in therapeutic gerontology.

\section{Acknowledgments}

This work was sponsored by grants from the Swedish Cancer Foundation, the Knut and Alice Wallenberg Foundation (Wallenberg Scholar Award), an Advanced ERC grant (QualiAGE), and the Science Faculty at the University of Gothenburg to T.N., and grants from the Swedish Research Council (VR), the Foundation of Olle Engkvist byggmästare, the Carl Trygger Foundation, and the Magnus Bergvall Foundation to M.M.

\section{References}

Anderson RM, Bitterman KJ, Wood JG, Medvedik O, Sinclair DA. 2003. Nicotinamide and PNC1 govern lifespan extension by calorie restriction in Saccharomyces cerevisiae. Nature 423: 181-185.

Andres-Mateos E, Perier C, Zhang L, Blanchard-Fillion B, Greco TM, Thomas B, Ko HS, Sasaki M, Ischiropoulos H, Przedborski S, et al. 2007. DJ-1 gene deletion reveals that DJ-1 is an atypical peroxiredoxin-like peroxidase. Proc Natl Acad Sci 104: $14807-14812$.

Asha Devi S, Sagar Chandrasekar BK, Manjula KR, Ishii N. 2011. Grape seed proanthocyanidin lowers brain oxidative stress in adult and middle-aged rats. Exp Gerontol 46: 958-964.

Bartke A. 2011. Pleiotropic effects of growth hormone signaling in aging. Trends Endocrinol Metab 22: 437-442.

Berggren M, Gallegos A, Gasdaska JR, Gasdaska PY, Warneke J, Powis G. 1996. Thioredoxin and thioredoxin reductase gene expression in human tumors and cell lines, and the effects of serum stimulation and hypoxia. Anticancer Res 16: 34593466.

Biteau B, Labarre J, Toledano MB. 2003. ATP-dependent reduction of cysteine-sulphinic acid by $S$. cerevisiae sulphiredoxin. Nature 425: 980-984.

Budanov AV, Sablina AA, Feinstein E, Koonin EV, Chumakov PM. 2004. Regeneration of peroxiredoxins by p53-regulated sestrins, homologs of bacterial AhpD. Science 304: 596-600.

Caballero A, Ugidos A, Liu B, Oling D, Kvint K, Hao X, Mignat C, Nachin L, Molin M, Nystrom T. 2011. Absence of mitochondrial translation control proteins extends life span by activating sirtuin-dependent silencing. Mol Cell 42: 390400.

Cao J, Schulte J, Knight A, Leslie NR, Zagozdzon A, Bronson R, Manevich Y, Beeson C, Neumann CA. 2009. Prdx1 inhibits tumorigenesis via regulating PTEN/AKT activity. EMBO J 28: 1505-1517.

Chen MF, Keng PC, Shau H, Wu CT, Hu YC, Liao SK, Chen WC. 2006. Inhibition of lung tumor growth and augmentation of radiosensitivity by decreasing peroxiredoxin I expression. Int J Radiat Oncol Biol Phys 64: 581-591.

Chung YM, Yoo YD, Park JK, Kim YT, Kim HJ. 2001. Increased expression of peroxiredoxin II confers resistance to cisplatin. Anticancer Res 21: 1129-1133.

Cohen E, Dillin A. 2008. The insulin paradox: Aging, proteotoxicity and neurodegeneration. Nat Rev Neurosci 9: 759-767.

Dang W, Steffen KK, Perry R, Dorsey JA, Johnson FB, Shilatifard A, Kaeberlein M, Kennedy BK, Berger SL. 2009. Histone H4 lysine 16 acetylation regulates cellular lifespan. Nature 459: 802-807.

D'Autreaux B, Toledano MB. 2007. ROS as signalling molecules: Mechanisms that generate specificity in ROS homeostasis. Nat Rev Mol Cell Biol 8: 813-824.

Davidson MB, Katou Y, Keszthelyi A, Sing TL, Xia T, Ou J, Vaisica JA, Thevakumaran N, Marjavaara L, Myers CL, et al. 2012. Endogenous DNA replication stress results in expansion of dNTP pools and a mutator phenotype. EMBO $J$ 31: 895-907.

Day AM, Brown JD, Taylor SR, Rand JD, Morgan BA, Veal EA. 2012. Inactivation of a peroxiredoxin by hydrogen peroxide is critical for thioredoxin-mediated repair of oxidized proteins and cell survival. Mol Cell 45: 398-408.

Egler RA, Fernandes E, Rothermund K, Sereika S, de SouzaPinto N, Jaruga P, Dizdaroglu M, Prochownik EV. 2005. Regulation of reactive oxygen species, DNA damage, and c-Myc function by peroxiredoxin 1. Oncogene 24: 80388050.

Erjavec N, Nystrom T. 2007. Sir2p-dependent protein segregation gives rise to a superior reactive oxygen species management in the progeny of Saccharomyces cerevisiae. Proc Natl Acad Sci 104: 10877-10881.

Fontana L, Partridge L, Longo VD. 2010. Extending healthy life span-from yeast to humans. Science 328: 321-326.

Fourquet S, Huang ME, D'Autreaux B, Toledano MB. 2008. The dual functions of thiol-based peroxidases in $\mathrm{H}_{2} \mathrm{O}_{2}$ scavenging and signaling. Antioxid Redox Signal 10: 1565-1576.

Friedman DB, Johnson TE. 1988. A mutation in the age-1 gene in Caenorhabditis elegans lengthens life and reduces hermaphrodite fertility. Genetics 118: 75-86.

Gallegos A, Gasdaska JR, Taylor CW, Paine-Murrieta GD, Goodman D, Gasdaska PY, Berggren M, Briehl MM, Powis G. 1996. Transfection with human thioredoxin increases cell proliferation and a dominant-negative mutant thioredoxin reverses the transformed phenotype of human breast cancer cells. Cancer Res 56: 5765-5770. 
Guarente L. 2000. Sir2 links chromatin silencing, metabolism, and aging. Genes Dev 14: 1021-1026.

Guarente L. 2011. Sirtuins, aging, and metabolism. Cold Spring Harb Symp Quant Biol 76: 81-90.

Hall A, Nelson K, Poole LB, Karplus PA. 2011. Structure-based insights into the catalytic power and conformational dexterity of peroxiredoxins. Antioxid Redox Signal 15: 795-815.

Hamilton WD. 1966. The moulding of senescence by natural selection. J Theor Biol 12: 12-45.

Harman D. 2003. The free radical theory of aging. Antioxid Redox Signal 5: 557-561.

Huang ME, Kolodner RD. 2005. A biological network in Saccharomyces cerevisiae prevents the deleterious effects of endogenous oxidative DNA damage. Mol Cell 17: 709-720.

Iraqui I, Faye G, Ragu S, Masurel-Heneman A, Kolodner RD, Huang ME. 2008. Human peroxiredoxin PrxI is an orthologue of yeast Tsal, capable of suppressing genome instability in Saccharomyces cerevisiae. Cancer Res 68: 10551063.

Iraqui I, Kienda G, Soeur J, Faye G, Baldacci G, Kolodner RD, Huang ME. 2009. Peroxiredoxin Tsal is the key peroxidase suppressing genome instability and protecting against cell death in Saccharomyces cerevisiae. PLoS Genet 5: e1000524. doi: 10.1371/journal.pgen.1000524.

Iriyama $\mathrm{T}$, Takeda $\mathrm{K}$, Nakamura $\mathrm{H}$, Morimoto $\mathrm{Y}$, Kuroiwa $\mathrm{T}$, Mizukami J, Umeda T, Noguchi T, Naguro I, Nishitoh $H$, et al. 2009. ASK1 and ASK2 differentially regulate the counteracting roles of apoptosis and inflammation in tumorigenesis. $E M B O /$ 28: 843-853.

Jang HH, Lee KO, Chi YH, Jung BG, Park SK, Park JH, Lee JR, Lee SS, Moon JC, Yun JW, et al. 2004. Two enzymes in one; two yeast peroxiredoxins display oxidative stress-dependent switching from a peroxidase to a molecular chaperone function. Cell 117: 625-635.

Jazwinski SM. 2002. Growing old: Metabolic control and yeast aging. Annu Rev Microbiol 56: 769-792.

Kaeberlein M, McVey M, Guarente L. 1999. The SIR2/3/4 complex and SIR2 alone promote longevity in Saccharomyces cerevisiae by two different mechanisms. Genes Dev 13: 2570-2580.

Kaeberlein M, Kirkland KT, Fields S, Kennedy BK. 2004. Sir2independent life span extension by calorie restriction in yeast. PLOS Biol 2: e296. doi: 10.1371/journal.pbio.0020296.

Kenyon CJ. 2010. The genetics of ageing. Nature 464: 504-512.

Kim SY, Kim TJ, Lee KY. 2008. A novel function of peroxiredoxin 1 (Prx-1) in apoptosis signal-regulating kinase 1 (ASK1)-mediated signaling pathway. FEBS Lett 582: 19131918.

Klass MR. 1983. A method for the isolation of longevity mutants in the nematode Caenorhabditis elegans and initial results. Mech Ageing Dev 22: 279-286.

Laun P, Pichova A, Madeo F, Fuchs J, Ellinger A, Kohlwein S, Dawes I, Frohlich KU, Breitenbach M. 2001. Aged mother cells of Saccharomyces cerevisiae show markers of oxidative stress and apoptosis. Mol Microbiol 39: 1166-1173.

Lee KS, Iijima-Ando K, Iijima K, Lee WJ, Lee JH, Yu K, Lee DS. 2009. JNK/FOXO-mediated neuronal expression of fly homologue of peroxiredoxin II reduces oxidative stress and extends life span. J Biol Chem 284: 29454-29461.

Lim JC, Choi HI, Park YS, Nam HW, Woo HA, Kwon KS, Kim YS, Rhee SG, Kim K, Chae HZ. 2008. Irreversible oxidation of the active-site cysteine of peroxiredoxin to cysteine sulfonic acid for enhanced molecular chaperone activity. I Biol Chem 283: 28873-28880.

Lindstrom DL, Leverich CK, Henderson KA, Gottschling DE. 2011. Replicative age induces mitotic recombination in the ribosomal RNA gene cluster of Saccharomyces cerevisiae. PLoS Genet 7: e1002015. doi: 10.1371/journal.pgen.1002015.

McCormick MA, Tsai SY, Kennedy BK. 2011. TOR and ageing: A complex pathway for a complex process. Philos Trans $R$ Soc Lond B Biol Sci 366: 17-27.

McMurray MA, Gottschling DE. 2003. An age-induced switch to a hyper-recombinational state. Science 301: 1908-1911.

McMurray MA, Gottschling DE. 2004. Aging and genetic instability in yeast. Curr Opin Microbiol 7: 673-679.

Medawar PB. 1952. An unsolved problem of biology: An inaugural lecture delivered at University College, London, 6 December, 1951. H.K. Lewis and Co., London.

Medvedik O, Lamming DW, Kim KD, Sinclair DA. 2007. MSN2 and MSN4 link calorie restriction and TOR to sirtuinmediated lifespan extension in Saccharomyces cerevisiae. PLoS Biol 5: e261. doi: 10.1371/journal.pbio.0050261.

Molin M, Yang J, Hanzen S, Toledano MB, Labarre J, Nystrom T. 2011. Life span extension and $\mathrm{H}_{2} \mathrm{O}_{2}$ resistance elicited by caloric restriction require the peroxiredoxin Tsal in Saccharomyces cerevisiae. Mol Cell 43: 823-833.

Mostoslavsky R, Chua KF, Lombard DB, Pang WW, Fischer MR, Gellon L, Liu P, Mostoslavsky G, Franco S, Murphy MM, et al. 2006. Genomic instability and aging-like phenotype in the absence of mammalian SIRT6. Cell 124: 315329.

Mu ZM, Yin XY, Prochownik EV. 2002. Pag, a putative tumor suppressor, interacts with the Myc Box II domain of c-Myc and selectively alters its biological function and target gene expression. J Biol Chem 277: 43175-43184.

Musicco C, Capelli V, Pesce V, Timperio AM, Calvani M, Mosconi L, Zolla L, Cantatore P, Gadaleta MN. 2009. Accumulation of overoxidized peroxiredoxin III in aged rat liver mitochondria. Biochim Biophys Acta 1787: 890896.

Neumann CA, Fang Q. 2007. Are peroxiredoxins tumor suppressors? Curr Opin Pharmacol 7: 375-380.

Neumann CA, Krause DS, Carman CV, Das S, Dubey DP, Abraham JL, Bronson RT, Fujiwara Y, Orkin SH, Van Etten RA. 2003. Essential role for the peroxiredoxin Prdxl in erythrocyte antioxidant defence and tumour suppression. Nature 424: 561-565.

Niida H, Shimada M, Murakami H, Nakanishi M. 2010. Mechanisms of dNTP supply that play an essential role in maintaining genome integrity in eukaryotic cells. Cancer Sci 101: 2505-2509.

Noh DY, Ahn SJ, Lee RA, Kim SW, Park IA, Chae HZ. 2001. Overexpression of peroxiredoxin in human breast cancer. Anticancer Res 21: 2085-2090.

Northam MR, Robinson HA, Kochenova OV, Shcherbakova PV. 2010. Participation of DNA polymerase zeta in replication of undamaged DNA in Saccharomyces cerevisiae. Genetics 184: $27-42$.

Oberdoerffer P, Michan S, McVay M, Mostoslavsky R, Vann J, Park SK, Hartlerode A, Stegmuller J, Hafner A, Loerch P, et al. 2008. SIRT1 redistribution on chromatin promotes genomic stability but alters gene expression during aging. Cell 135: 907-918.

Olahova M, Taylor SR, Khazaipoul S, Wang J, Morgan BA, Matsumoto K, Blackwell TK, Veal EA. 2008. A redoxsensitive peroxiredoxin that is important for longevity has tissue- and stress-specific roles in stress resistance. Proc Natl Acad Sci 105: 19839-19844.

Park JH, Kim YS, Lee HL, Shim JY, Lee KS, Oh YJ, Shin SS, Choi YH, Park KJ, Park RW, et al. 2006. Expression of peroxiredoxin and thioredoxin in human lung cancer and paired normal lung. Respirology 11: 269-275. 
Poli J, Tsaponina O, Crabbe L, Keszthelyi A, Pantesco V, Chabes A, Lengronne A, Pasero P. 2012. dNTP pools determine fork progression and origin usage under replication stress. EMBO J 31: 883-894.

Powis G, Kirkpatrick DL. 2007. Thioredoxin signaling as a target for cancer therapy. Curr Opin Pharmacol 7: 392-397.

Ragu S, Faye G, Iraqui I, Masurel-Heneman A, Kolodner RD, Huang ME. 2007. Oxygen metabolism and reactive oxygen species cause chromosomal rearrangements and cell death. Proc Natl Acad Sci 104: 9747-9752.

Ramanathan RK, Kirkpatrick DL, Belani CP, Friedland D, Green SB, Chow H-HS, Cordova CA, Stratton SP, Sharlow ER, Baker A, et al. 2007. A phase I pharmacokinetic and pharmacodynamic study of PX-12, a novel inhibitor of thioredoxin-1, in patients with advanced solid tumors. Clin Cancer Res 13: 2109-2114.

Rattan SI. 1995. Gerontogenes: Real or virtual? FASEB J 9: 284286.

Rhee SG, Woo HA, Kil IS, Bae SH. 2012. Peroxiredoxin functions as a peroxidase and a regulator and sensor of local peroxides. I Biol Chem 287: 4403-4410.

Sabouri N, Viberg J, Goyal DK, Johansson E, Chabes A. 2008. Evidence for lesion bypass by yeast replicative DNA polymerases during DNA damage. Nucleic Acids Res 36: 56605667.

Saccoccia F, Di Micco P, Boumis G, Brunori M, Koutris I, Miele AE, Morea V, Sriratana P, Williams DL, Bellelli A, et al. 2012. Moonlighting by different stressors: Crystal structure of the chaperone species of a 2-Cys peroxiredoxin. Structure 20: 429-439.

Sinclair DA, Guarente L. 1997. Extrachromosomal rDNA circles-a cause of aging in yeast. Cell 91: 1033-1042.

Steffen KK, MacKay VL, Kerr EO, Tsuchiya M, Hu D, Fox LA, Dang N, Johnston ED, Oakes JA, Tchao BN, et al. 2008. Yeast life span extension by depletion of 60 s ribosomal subunits is mediated by Gen4. Cell 133: 292-302.

Suh Y, Atzmon G, Cho MO, Hwang D, Liu B, Leahy DJ, Barzilai N, Cohen P. 2008. Functionally significant insulin-like growth factor I receptor mutations in centenarians. Proc Natl Acad Sci 105: 3438-3442.

Tang HM, Siu KL, Wong CM, Jin DY. 2009. Loss of yeast peroxiredoxin Tsalp induces genome instability through activation of the DNA damage checkpoint and elevation of dNTP levels. PLoS Genet 5: e1000697. doi: 10.1371/journal. pgen.1000697.

Thamsen M, Kumsta C, Li F, Jakob U. 2011. Is overoxidation of peroxiredoxin physiologically significant? Antioxid Redox Signal 14: 725-730.

Timmermann B, Jarolim S, Russmayer H, Kerick M, Michel S, Kruger A, Bluemlein K, Laun P, Grillari J, Lehrach H, et al. 2010. A new dominant peroxiredoxin allele identified by whole-genome re-sequencing of random mutagenized yeast causes oxidant-resistance and premature aging. Aging (Albany NY) 2: 475-486.

Veatch JR, McMurray MA, Nelson ZW, Gottschling DE. 2009. Mitochondrial dysfunction leads to nuclear genome instability via an iron-sulfur cluster defect. Cell 137: 1247-1258.

Wei Q, Jiang H, Matthews CP, Colburn NH. 2008. Sulfiredoxin is an AP-1 target gene that is required for transformation and shows elevated expression in human skin malignancies. Proc Natl Acad Sci 105: 19738-19743.

Wei Q, Jiang H, Xiao Z, Baker A, Young MR, Veenstra TD, Colburn NH. 2011. Sulfiredoxin-peroxiredoxin IV axis promotes human lung cancer progression through modulation of specific phosphokinase signaling. Proc Natl Acad Sci 108: 7004-7009.
Wen ST, Van Etten RA. 1997. The PAG gene product, a stressinduced protein with antioxidant properties, is an Abl SH3binding protein and a physiological inhibitor of c-Abl tyrosine kinase activity. Genes Dev 11: 2456-2467.

Woo HA, Jeong W, Chang TS, Park KJ, Park SJ, Yang JS, Rhee SG. 2005. Reduction of cysteine sulfinic acid by sulfiredoxin is specific to 2-cys peroxiredoxins. I Biol Chem 280: 31253128.

Woo HA, Bae SH, Park S, Rhee SG. 2009. Sestrin 2 is not a reductase for cysteine sulfinic acid of peroxiredoxins. Antioxid Redox Signal 11: 739-745.

Woo HA, Yim SH, Shin DH, Kang D, Yu DY, Rhee SG. 2010. Inactivation of peroxiredoxin I by phosphorylation allows localized $\mathrm{H}_{2} \mathrm{O}_{2}$ accumulation for cell signaling. Cell 140: 517-528.

Wood ZA, Poole LB, Karplus PA. 2003a. Peroxiredoxin evolution and the regulation of hydrogen peroxide signaling. Science 300: 650-653.

Wood ZA, Schroder E, Robin Harris J, Poole LB. 2003b. Structure, mechanism and regulation of peroxiredoxins. Trends Biochem Sci 28: 32-40. 


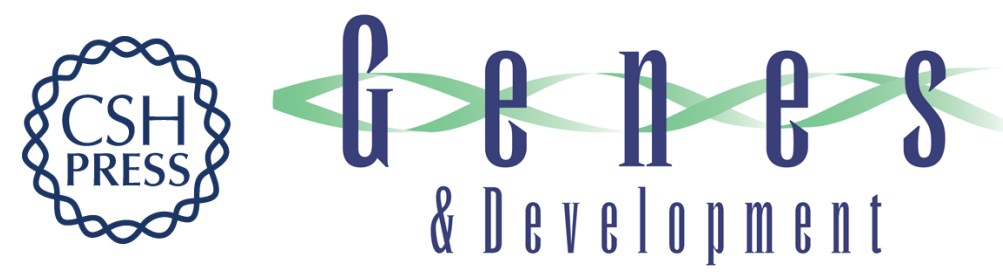

\section{Peroxiredoxins, gerontogenes linking aging to genome instability and cancer}

Thomas Nyström, Junsheng Yang and Mikael Molin

Genes Dev. 2012, 26:

Access the most recent version at doi:10.1101/gad.200006.112

References This article cites 81 articles, 23 of which can be accessed free at: http://genesdev.cshlp.org/content/26/18/2001.full.html\#ref-list-1

License

Email Alerting

Receive free email alerts when new articles cite this article - sign up in the box at the top Service right corner of the article or click here.

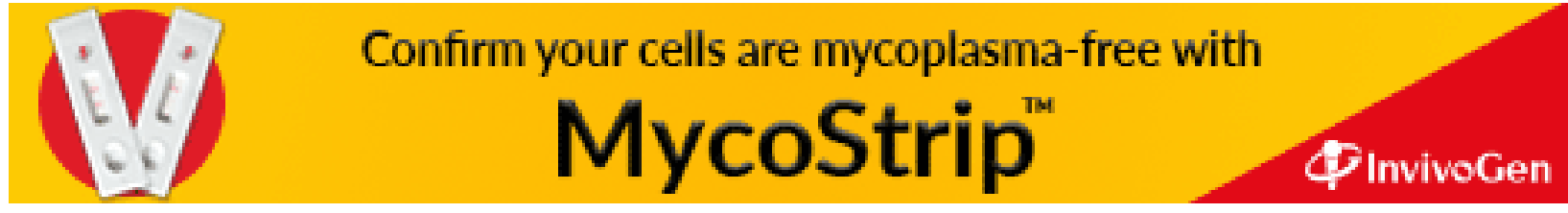

